\title{
The Mediterranean diet in relation to mortality and CVD: a Danish cohort study
}

\author{
Gianluca Tognon $^{1 *}$, Lauren Lissner ${ }^{1}$, Ditte Sæbye ${ }^{2}$, Karen Z. Walker ${ }^{3}$ and Berit L. Heitmann ${ }^{2,4,5}$ \\ ${ }^{1}$ Public Health Epidemiology Unit, Department of Public Health and Community Medicine, University of Gothenburg, \\ Sablgrenska Academy, Box 454, SE 405 30, Göteborg, Sweden \\ ${ }^{2}$ Research Unit for Dietary Studies at the Institute of Preventive Medicine, Bispebjerg and Frederiksberg Hospitals - a part of \\ Copenhagen University Hospital, The Capital Region, Copenhagen, Denmark \\ ${ }^{3}$ Department of Nutrition and Dietetics, Monash University, Melbourne, VIC, Australia \\ ${ }^{4}$ National Institute of Public Health, University of Southern Denmark, Denmark \\ ${ }^{5}$ Research Centre for Prevention and Health, Copenhagen University Hospital Glostrup, The Capital Region of Denmark, Denmark
}

(Submitted 2 January 2013 - Final revision received 15 May 2013 - Accepted 17 May 2013 - First published online 3 July 2013)

\section{Abstract}

The aim of the present study was to determine whether the Mediterranean Diet Score (MDS) is associated with reduced total mortality, cardiovascular incidence and mortality in a Danish population. Analyses were performed on 1849 men and women sampled during the 1982-83 Danish MONICA (MONItoring trends and determinants of Cardiovascular disease) population study, whose diet was assessed by means of a validated $7 \mathrm{~d}$ food record. The adherence to a Mediterranean dietary pattern was calculated by three different scores: one based on a classification excluding ingredients from mixed dishes and recipes (score 1); another based on a classification including ingredients (score 2); the last one based on a variant of the latter including wine instead of alcohol intake (score 3). The association between these scores and, respectively, total mortality, cardiovascular incidence and mortality was tested by a Cox proportional hazards model adjusted for several potential confounders of the association. Generally, all three scores were inversely associated with the endpoints, although associations with score 1 did not reach statistical significance. Score 2 was inversely associated with total mortality (hazard ratio 0.94; 95\% CI 0.88, 0.99). This association was confirmed for total cardiovascular as well as myocardial infarction (MI) incidence and mortality, but not for stroke. Score 3 was slightly more associated with the same outcomes. All associations were also resistant to adjustment for covariates related to potential CVD pathways, such as blood lipids, blood pressure and weight change after 11 years of follow-up. In a Danish cohort, the MDS was inversely associated with total mortality and with cardiovascular and MI incidence and mortality, but not with stroke incidence or mortality.

\section{Key words: Mediterranean diet: Mortality: Cardiovascular incidence: Mortality}

Lifestyle and eating habits are key modifiable factors that people can change to decrease chronic disease risk. Poor diet, in particular, has been convincingly linked to the incidence of CVD and some forms of cancer ${ }^{(1,2)}$, which are responsible for most of the disease burdens in the majority of developed countries ${ }^{(3)}$.

Dietary recommendations promoting healthy dietary patterns including whole-grain foods, legumes, vegetables and fruit, and suggesting that the intake of full-fat dairy products, sweets and red meat be limited, are an emerging approach for the prevention of several diseases, and the Mediterranean-style diet embodies many of these recommendations ${ }^{(4)}$. Indeed, in a recent meta-analysis, the Mediterranean eating pattern has turned out to be more effective than low-fat diets in inducing important long-term changes in cardiovascular risk factors and inflammatory markers ${ }^{(5)}$.

Greater adherence to a Mediterranean-like dietary pattern, in particular, has been shown to be associated with improvement in health status ${ }^{(6,7)}$ as well as inversely associated with both premature $^{(8)}$ and total mortality ${ }^{(9,10)}$. The latter effect has been observed in countries both inside ${ }^{(11)}$ and outside ${ }^{(12-14)}$ the Mediterranean basin, for instance, in Nordic countries ${ }^{(12)}$, where we recently reported an inverse association with mortality both in elderly ${ }^{(15,16)}$ and in middle-aged adults living in Sweden ${ }^{(17)}$.

Dietary patterns in the Mediterranean countries are changing rapidly, with an increased consumption of animal products and saturated fats and a decline in the intake of vegetable-based foodstuffs ${ }^{(18-20)}$. On the other hand,

Abbreviations: FIL, food intake level; HR, hazard ratio; MDS, Mediterranean Diet Score; MI, myocardial infarction; PAL, physical activity level.

*Corresponding author: G. Tognon, fax + 46317781704 , email gianluca.tognon@gu.se 
Nordic populations have paradoxically increased their intakes of typical Mediterranean items such as fruit, vegetables and wine between 1970 and mid-2000 (21-23).

The aim of the present study was to determine whether the Mediterranean Diet Score (MDS) was inversely associated with all-cause mortality as well as cardiovascular incidence and mortality in the Danish MONICA (MONItoring trends and determinants of Cardiovascular disease) population study.

\section{Subjects and methods}

\section{Subjects and measures}

In 1982, a sample of 4807 subjects was randomly selected from the Central Person Register of citizens born in 1922, 1932, 1942 and 1952 living in eleven municipalities in the Copenhagen County ${ }^{(24)}$. Of these, 226 were of non-Danish origin. Among the 4581 invited, 3608 participated in a subsequent health examination in $1982-3^{(25)}$. The non-respondents have been described in detail elsewhere ${ }^{(26)}$. The present study was part of the Danish MONICA project, an international study conducted under the auspices of the WHO to monitor CVD trends and determinants. One subject was excluded due to missing BMI information at baseline and three subjects for missing blood test results. The cohort described here included 1849 subjects (948 women) with complete information on diet intake and anthropometry and 1348 subjects (701 women) who also had results for blood tests and blood pressure.

The participants filled in a questionnaire describing their highest grade of education or highest year of regular schooling classified into $0-7,8-11$ and $\geq 12$ years, their cigarette smoking habits and their leisure time activity. The latter was categorised into four classes: inactive; light ( $<4 \mathrm{~h} /$ week); moderate ( $>4 \mathrm{~h} /$ week); energetic ( $>4 \mathrm{~h} /$ week).

Body weight was measured to the nearest $0 \cdot 1 \mathrm{~kg}$ using a lever balance, with subjects dressed in light clothing or underwear. Height was measured without shoes to the nearest $1 \mathrm{~cm}$. Weight change information after 11 years of follow-up was available for a subsample of 1348 subjects.

BMR (kcal/d) was calculated according to Schofield equations for subjects aged $30-59$ years ${ }^{(27)}$ :

$$
\begin{aligned}
& \mathrm{BMR}=11.5 \text { weight }(\mathrm{kg})+873(\text { men }) . \\
& \mathrm{BMR}=8.3 \text { weight }(\mathrm{kg})+846(\text { women }) .
\end{aligned}
$$

Food intake level (FIL) was then calculated based on the ratio of reported energy intake to BMR. Both systolic and diastolic blood pressures were measured with a London School of Hygiene sphygmomanometer, using one of the three different cuffs. Duplicate measurements were taken on the left arm after a minimum of $5 \mathrm{~min}$ of rest in a supine position. Means of duplicate measures were calculated and used in the analyses described below. Blood samples were drawn after a $12 \mathrm{~h}$ overnight fast. A commercial enzymatic method was used (Boehringer Mannheim) to measure the concentrations of total cholesterol, HDL-cholesterol and TAG (mmol/l) in the serum $^{(28)}$. The total cholesterol:HDL-cholesterol ratio was calculated, and a value greater than 4 was arbitrarily chosen as a threshold of a risky lipid profile.

\section{Dietary assessment}

Information on diet was obtained by means of a four-page (A3 format) weighed $7 \mathrm{~d}$ food record. The front page contained instructions for correct completion of the diet records together with the average household weights of nineteen frequently consumed foods, e.g. the white of an egg and a slice of bread. For butter and liver pâté, three examples were given of typical amounts put on a slice of bread. On the next pages, 100 foods were listed in the following nine subgroups: dairy products; bread and cereal grains; fats; cold cuts, etc.; vegetables; fruit; meat (including poultry and fish); drinks; miscellaneous items. The last page included space to record foods that did not fit into any of the nine groups, such as mixed dishes, home-made salads and cakes.

The participants were also given thorough verbal instructions on how to fill out the food record. It was emphasised that the diet record be completed during a typical $7 \mathrm{~d}$ period including a minimum of non-habitual social activities. Food quantities were expressed in grams, estimated as accurately as possible or preferably weighed. The same trained dietitian manually checked and coded all food records into dietary components.

\section{Definitions of food groups and of the Mediterranean Diet Score}

To assess the association of diet and lifestyle factors with all-cause mortality, a version of the modified $\operatorname{MDS}^{(29)}$ adapted to the MONICA diet questionnaire was calculated. The score comprised eight positive or negative components: (1) ratio of (monounsaturated + polyunsaturated):saturated fats; (2) vegetables; (3) fruit; (4) cereal grains; (5) fish and fish products; (6) alcohol intake; (7) meat, meat products and eggs (negative); (8) dairy products (negative). As has been described previously $^{(9,29)}$, the intake of each component was adjusted to the daily energy intakes of $10 \cdot 467 \mathrm{~kJ}(2500 \mathrm{kcal})$ for men and $8.374 \mathrm{~kJ}(2000 \mathrm{kcal})$ for women, in order to obtain energyadjusted associations in all the analyses. As sex-specific median intakes were taken as cut-off points, the final score must be considered as a measure of relative adherence to the Mediterranean dietary pattern. A value of 1 was assigned to subjects whose consumption was higher than the sexspecific median and 0 to the others, with the exception of meat and dairy products, where the reverse rule was applied. The final score was obtained by summing these values, and it varied from 0 (low adherence) to 8 (high adherence). Food groups were defined based on two different procedures, from which two different scores were produced. The first procedure included the identification of all the possible food items that could be classified according to the above-mentioned food categories (vegetables, fruit, etc.), but excluding mixed dishes (score 1). The second procedure included food items classified into food groups as in score 1, but now including ingredients extrapolated from mixed dishes or recipes (score 2). Finally, a variant of score 2 was created, now including wine instead of total alcohol intake (score 3). 


\section{Endpoints}

Information on all-cause mortality as well as on CVD or myocardial infarction (MI) incidence and mortality was retrieved from the National Patient Registry of Hospital Discharges, the Cause of Death Register and the Central Person Register. The subjects were followed until 8 July 2007 for an average of 14 years. Survival time was parameterised in terms of lifetime until death or censoring event in years, with left truncation at the age of entrance into the study being equal to baseline examination. Total CVD cases were identified based on codes 390-458 (ICD8) and I00-I99 (ICD10) and MI cases were identified based on codes 410 (ICD8) and I21 (ICD10), while stroke cases were identified based on codes 430-434 + 436 (ICD8) and I60-I64 (ICD10). Analyses on CVD, MI and stroke incidence (both fatal and non-fatal cases) and mortality were performed given that there was no CVD, MI or stroke at baseline.

\section{Statistical analyses}

The associations of the three above-mentioned diet scores with mortality were determined by means of Cox proportional hazards models, either adjusted only by age or adjusted for potential confounders such as sex, age, obesity, smoking status (two dummy variables were included, describing pack years greater than 0 but less than 30 and pack years greater than 30, keeping the 'never smoked' category as the reference), education (the lowest level $v$. higher levels) and physical activity (see the above-mentioned categories). The latter model was then considered the main model. Additionally, in order to determine possible pathways of effects, we performed some confirmatory analyses adjusting for blood pressure (systolic and diastolic, included as continuous variables), blood lipids (TAG, included as a continuous variable, and total cholesterol:HDL-cholesterol ratio $>4$ ) and weight change (including two dummy variables describing weight change $>3 \mathrm{~kg}$ or $<-3 \mathrm{~kg}$ and keeping a weight change of 0 to $\pm 3 \mathrm{~kg}$ as the reference category). All-cause mortality as well as cause-specific incidence and mortality, i.e. total CVD, MI and stroke, were studied in association with the MDS.

Effect modification of exposure (MDS) by each covariate was tested in the main model by including interaction terms. Stratified estimates were calculated in case a significant interaction was found. The association of single components of the MDS was also tested separately, by including as exposure a variable describing an intake over the sex-specific medians (fat ratio, vegetables, fruit, cereal grains, fish and alcohol) or below the median (meat and dairy products). To reduce bias for changes in diet or lifestyle factors due to subclinical disease, the main model was also run after excluding the first 2 years of follow-up. In analyses, different versions of the MDS were included, and these were excluded one at a time, and also single components of these scores were tested (while keeping all other components) in order to determine whether any associations could be explained by a single component.

With the aim of determining the additive effects of an increasing number of risk factors such as ever been a smoker, having a low physical activity level (PAL) $(<4 \mathrm{~h} /$ week $)$ and obesity (BMI $\geq 30 \mathrm{~kg} / \mathrm{m}^{2}$ ) and not consuming a Mediterranean-like diet (MDS $\leq 4$ ), a new score was calculated, assigning an additional point for each of the above-mentioned risk factors. Different hazard ratios (HR) and 95\% CI describing the association (adjusted by sex) of each level of the score with all-cause mortality were calculated and depicted in a histogram.

A sensitivity analysis was performed, aiming to confirm the main results in a subsample of subjects who could be considered 'adequate reporters'. The ratio of FIL:PAL was calculated. Adequate reporters were defined according to three different definitions based on increasingly stringent criteria, i.e. exclusion of the lowest 30\% (less stringent criterion) and of the lowest $50 \%$ and of the lowest $65 \%$ of the FIL:PAL ratio (most stringent criteria).

Statistical analyses were performed with SAS software (version 9.0; SAS Institute). All tests were considered significant if $P<0 \cdot 05$.

\section{Bioethics}

The present study was conducted according to the guidelines laid down in the Declaration of Helsinki (1989) of the World Medical Association, and all procedures involving human subjects were approved by the Ethics Committee of the Medicine Faculty of the Copenhagen County. All subjects were informed of the aims and procedures of the study, and they gave their written consent.

\section{Results}

\section{Cohort description}

The population consisted of 948 women (51.3\%) and 901 men (48.7\%). Only a small number were obese ( $n$ 138, 7.5\%).

Table 1. Intake value of each food group included in the Mediterranean Diet Score, adjusted to $8.374 \mathrm{MJ}(2000 \mathrm{kcal})$ in women and $10.467 \mathrm{MJ}$ $(2500 \mathrm{kcal})$ in men*

(Medians with their 5th-95th percentiles)

\begin{tabular}{|c|c|c|}
\hline & Median & $\begin{array}{l}\text { 5th-95th } \\
\text { percentile }\end{array}$ \\
\hline $\begin{array}{l}\text { (Monounsaturated + polyunsaturated): } \\
\text { saturated fats }\end{array}$ & $1 \cdot 1$ & $0.8-1.6$ \\
\hline Vegetables (g/d) & $192 \cdot 1$ & $79 \cdot 0-418 \cdot 5$ \\
\hline Fruit (g/d) & $109 \cdot 8$ & $0-401 \cdot 5$ \\
\hline Cereal grains $(\mathrm{g} / \mathrm{d})$ & $179 \cdot 9$ & $94 \cdot 3-297 \cdot 0$ \\
\hline Fish and shellfish (g/d) & $25 \cdot 2$ & $0-87 \cdot 5$ \\
\hline Alcohol among users (g/d) & $15 \cdot 5$ & $2 \cdot 0-62 \cdot 6$ \\
\hline Wine among users $(\mathrm{g} / \mathrm{d})$ & 2.5 & $0.8-13.0$ \\
\hline Dairy products $(\mathrm{g} / \mathrm{d})$ & $297 \cdot 4$ & $55 \cdot 0-750 \cdot 6$ \\
\hline Meat products $(\mathrm{g} / \mathrm{d})$ & $182 \cdot 3$ & $95 \cdot 6-310 \cdot 5$ \\
\hline Energy intake $(\mathrm{kJ} / \mathrm{d})$ in men & $10571 \cdot 7$ & $6514 \cdot 7-15993 \cdot 6$ \\
\hline Energy intake $(\mathrm{kJ} / \mathrm{d})$ in women & $7460 \cdot 9$ & $4450 \cdot 6-11852 \cdot 8$ \\
\hline FIL (energy intake:BMR) & 1.4 & $0.8-2 \cdot 1$ \\
\hline Mediterranean Diet Score 1 & 5 & $2-7$ \\
\hline Mediterranean Diet Score 2 & 4 & $2-6$ \\
\hline Mediterranean Diet Score 3 & 4 & $2-6$ \\
\hline
\end{tabular}

FIL, food intake level.

* Energy intake and the ratio of energy intake:BMR are also reported. 
A total of $476(25.7 \%)$ had never smoked cigarettes, while 303 (16.4\%) smoked more than thirty pack years. Finally, 241 subjects (13\%) abstained from any alcohol intake. Among the cardiovascular risk factors, 450 subjects $(24.3 \%)$ had high blood pressure (either systolic $\geq 140 \mathrm{mmHg}$ or diastolic $\geq 90 \mathrm{mmHg}$ ), almost half of the population had either a total cholesterol:HDL-cholesterol ratio $>4$ ( $n$ 955, 51.6\%), while about a third had gained more than $3 \mathrm{~kg}$ at follow-up (n 666, 36.0\%).

Energy-adjusted median values of each score component (Table 1) showed that the ratio of unsaturated:saturated fats was $1 \cdot 1$ (5th-95th percentiles: $0 \cdot 8-1 \cdot 6)$, indicating a similar level of consumption of each type of fat. Vegetable intake was higher than fruit intake, while the median intake for dairy products was almost $300 \mathrm{~g} / \mathrm{d}$. Median alcohol intake among users was about one standard unit and a half $(15.5 \mathrm{~g} / \mathrm{d})$, while median wine intake was $2.5 \mathrm{~g} / \mathrm{d}$. The median reported daily energy intakes were $10571 \cdot 7 \mathrm{MJ}(2525 \mathrm{kcal})$ in men and $7460.9 \mathrm{MJ}(1782 \mathrm{kcal})$ in women. The ratio of energy intake:BMR was 1.4 (5th-95th percentiles: $0 \cdot 8-2 \cdot 1$ ), indicating a good estimation of energy intake compared with the metabolic rate. The differences among the median values of the three scores were very small.

\section{Main analyses and effect modification}

The association between the three different versions of the MDS (scores 1,2 and 3) and all-cause mortality as well as CVD incidence and mortality was assessed (Table 2), adjusting for only age or for different potential confounders such as sex, age, BMI, education, physical activity and cigarette smoking (main model). Since no statistical interaction $(P>0.05)$ with sex was found in relation to almost all outcomes, all analyses were conducted on men and women together, adjusting for sex.

Results were, in general, in the direction of an inverse association between the three scores and all the outcomes, with the exception that the association between the MDS calculated excluding mixed dishes and recipes (score 1) did not reach statistical significance in either the main model or in the age-only-adjusted model. In contrast, the second version of the MDS, including the ingredients from mixed dishes and recipes (score 2), was inversely associated with all outcomes except with stroke incidence (HR 0.96; $95 \%$ CI $0.86,1.07$ ) and mortality (HR $1.03 ; 95 \%$ CI $0.82,1.30$ ). In the age-only-adjusted model, score 2 was significantly associated only with CVD incidence and MI mortality. Finally, score 2, recalculated to include wine instead of total alcohol intake (score 3), was significantly associated with all outcomes, but, again, not with stroke.

No effect modification was found when testing the interaction with potential confounders, with the exception of the association between the MDS and MI mortality, which was significant only at low PAL (moderate activity $<4 \mathrm{~h} /$ week) (score 3: HR 0.61; $95 \%$ CI 0.43, 0.86; $P$ for interaction: $0 \cdot 04$ ).

In order to determine possible pathways of effects in relation to the cardiovascular risk, the main model was further adjusted for blood lipids and blood pressure as well as for 
the latter plus weight change (Table 3). With the exception of MI incidence, which did not resist the adjustment for weight change (HR 0.91; 95\% CI 0.79, 1.05), the results obtained after these additional adjustments were in line with the previous ones (main model, Table 2 ) or slightly stronger. Finally, the exclusion of early deaths (i.e. subjects who died during the first 2 years of follow-up) did not materially change the results, with the exception, again, of MI incidence, where association with the score was only of borderline significance (HR 0.91; $95 \%$ CI $0 \cdot 81,1 \cdot 02)$.

\section{Supplementary analyses}

Table 4 summarises the results of a supplementary analysis, where the association of all endpoints with different versions of score 3 was determined. The alternative versions were created by excluding, one at a time, each single score component to check if any of these could explain alone the association of the score. The results show that the association was robust, and in the few cases where the association was not significant, a borderline association was found. The association of single MDS components (high or low intake according to median values) with all the endpoints investigated revealed only a few significant results (Table 5). The most robust one was found with high fruit intake, which was inversely associated with all-cause mortality (HR 0.74; 95\% CI 0.62, 0.88), CVD incidence (HR 0.86; $95 \% \mathrm{CI}$ $0.75,1.00$ ) and mortality (HR $0.72 ; 95 \%$ CI $0.55,0.94$ ). Also, vegetables showed some significant associations with all-cause mortality (HR $0.81 ; 95 \%$ CI $0.68,0.96)$ as well as with MI incidence (HR $0.73 ; 95 \%$ CI $0.54,1.00)$ and mortality (HR 0.58; 95\% CI 0.35, 0.96).

The results of the sensitivity analyses, based on three different definitions of adequate diet reporters ( $>30 \%$ FIL:PAL, $>50 \%$ and $>65 \%$ ), showed that although score 3 was always inversely associated with both incidence and mortality, not all these analyses were statistically significant due to a highly reduced number of cases, especially when the most stringent criterion was applied ( $>65 \%$ FIL:PAL). No large variations of these estimates were observed comparing these three analyses. Both all-cause mortality and CVD mortality were shown to be the strongest associations, since they were statistically significant no matter how adequate diet reporters were defined.

\section{Mediterranean Diet Score and other lifestyle factors}

Diet and lifestyle are strongly associated, and the level of the MDS was associated with smoking status, obesity and physical activity. We determined the cumulative effect of diet and lifestyle-related risk factors on mortality (not to be confused with a dose response to the number of levels of the MDS) by means of an additional score (Fig. 1). With increased number of risk factors (i.e. ever been a smoker, having a low physical activity level, being obese and not consuming a Mediterranean-like diet) the mortality risk increased linearly. In the highest risk category (three or four risk factors) the sex-adjusted association will all-cause

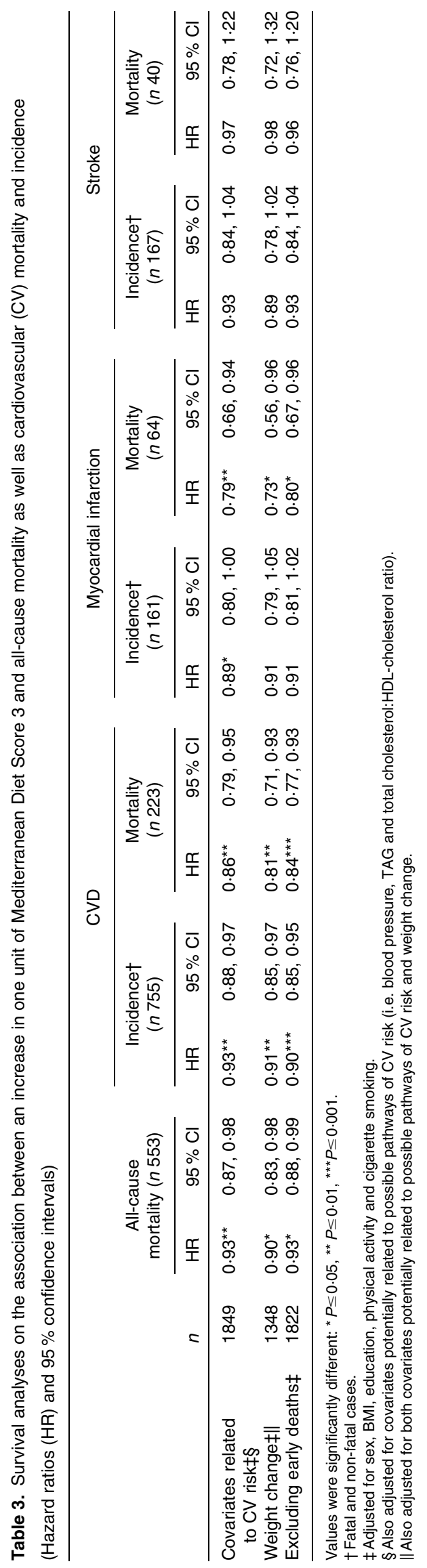


Table 4. Sensitivity analyses excluding, one at a time, each level of Mediterranean Diet Score (MDS) $3 \dagger$ (Hazard ratios (HR) and $95 \%$ confidence intervals)

\begin{tabular}{|c|c|c|c|c|c|c|c|c|c|c|c|c|c|c|}
\hline & & & \multicolumn{4}{|c|}{ CVD } & \multicolumn{4}{|c|}{ Myocardial infarction } & \multicolumn{4}{|c|}{ Stroke } \\
\hline & \multicolumn{2}{|c|}{$\begin{array}{l}\text { All-cause mortality } \\
\qquad(n 553)\end{array}$} & \multicolumn{2}{|c|}{$\begin{array}{l}\text { Incidence } \neq \\
\quad(n 755)\end{array}$} & \multicolumn{2}{|c|}{$\begin{array}{l}\text { Mortality } \\
\text { (n 223) }\end{array}$} & \multicolumn{2}{|c|}{$\begin{array}{l}\text { Incidence } \neq \\
\quad(n 161)\end{array}$} & \multicolumn{2}{|c|}{$\begin{array}{l}\text { Mortality } \\
(n 64)\end{array}$} & \multicolumn{2}{|c|}{$\begin{array}{l}\text { Incidence } \neq \\
\quad(n 167)\end{array}$} & \multicolumn{2}{|c|}{$\begin{array}{l}\text { Mortality } \\
(n \text { 40) }\end{array}$} \\
\hline & $\mathrm{HR}$ & $95 \% \mathrm{Cl}$ & $\mathrm{HR}$ & $95 \% \mathrm{Cl}$ & $\mathrm{HR}$ & $95 \% \mathrm{Cl}$ & $\mathrm{HR}$ & $95 \% \mathrm{Cl}$ & $\mathrm{HR}$ & $95 \% \mathrm{Cl}$ & $\mathrm{HR}$ & $95 \% \mathrm{Cl}$ & $\mathrm{HR}$ & $95 \% \mathrm{Cl}$ \\
\hline \multicolumn{15}{|c|}{ MDS recalculated excluding } \\
\hline Fat ratio & $0.92^{*}$ & $0.86,0.98$ & $0.91^{\star *}$ & $0.86,0.96$ & $0.85^{\star *}$ & $0.76,0.94$ & 0.91 & $0.80,1.03$ & $0.79^{*}$ & $0.65,0.96$ & 0.93 & $0.82,1.05$ & 0.92 & $0.71,1.18$ \\
\hline Vegetables & 0.94 & $0.89,1.01$ & $0.92^{\star *}$ & $0.87,0.97$ & $0 \cdot 88^{\star \star}$ & $0.79,0.97$ & 0.92 & $0.82,1.03$ & $0.82^{*}$ & $0.68,0.99$ & 0.93 & $0.83,1.04$ & 0.98 & $0.77,1.24$ \\
\hline Fruit & 0.96 & $0.90,1.02$ & $0.92^{\star \star}$ & $0.87,0.97$ & $0.89^{*}$ & $0.80,0.98$ & $0.88^{*}$ & $0.78,0.99$ & $0.77^{\star \star}$ & $0.64,0.93$ & 0.94 & $0.84,1.05$ & 1.04 & $0.82,1.32$ \\
\hline Cereal grains & $0.92^{*}$ & $0.86,0.98$ & $0.92^{\star \star}$ & $0.87,0.97$ & $0.88^{*}$ & $0.80,0.97$ & $0.89^{*}$ & $0.79,1.00$ & $0.80^{\star}$ & $0.66,0.96$ & 0.95 & $0.84,1.06$ & 0.96 & $0.75,1.22$ \\
\hline Fish and shellfish & $0.91^{\star \star}$ & $0.86,0.97$ & $0.92^{\star \star}$ & $0.87,0.97$ & $0.84^{\star \star \star}$ & $0.76,0.93$ & $0.88^{*}$ & $0.78,0.99$ & $0.75^{\star \star}$ & $0.62,0.91$ & 0.92 & $0.82,1.03$ & 0.92 & $0.72,1.17$ \\
\hline Wine & $0.92^{\star \star}$ & $0.87,0.98$ & $0.92^{\star \star}$ & $0.87,0.97$ & $0.87^{\star *}$ & $0.79,0.96$ & $0.89^{*}$ & $0.79,1.00$ & $0.76^{\star *}$ & $0.63,0.92$ & 0.92 & $0.82,1.03$ & 0.98 & $0.78,1.24$ \\
\hline Dairy products & $0.93^{\star}$ & $0.87,0.98$ & $0.91^{\star \star \star}$ & $0.87,0.96$ & $0.88^{\star \star}$ & $0.80,0.97$ & 0.90 & $0.80,1.01$ & 0.85 & $0.71,1.02$ & 0.93 & $0.83,1.04$ & 0.96 & $0.76,1.20$ \\
\hline Meat products & $0.92^{*}$ & $0.87,0.98$ & $0.92^{\star \star}$ & $0.87,0.97$ & $0.87^{\star \star}$ & $0.79,0.96$ & 0.90 & $0.80,1.01$ & $0.76^{\star \star}$ & $0.63,0.92$ & 0.94 & $0.84,1.05$ & 0.99 & $0.78,1.25$ \\
\hline
\end{tabular}

Values were significantly different: ${ }^{*} P \leq 0.05,{ }^{\star \star} P \leq 0.01,{ }^{\star \star \star} P \leq 0.001$

† All results were obtained from a Cox proportional hazards model, adjusted for sex, BMI, education, physical activity and cigarette smoking.

†Fatal and non-fatal cases.

Table 5. Survival analyses on the association between the intake of single food groups above or below the median and several outcomes related to all-cause mortality and cardiovascular incidence and mortality†

(Hazard ratios (HR) and $95 \%$ confidence intervals)

\begin{tabular}{|c|c|c|c|c|c|c|c|c|c|c|c|c|c|c|}
\hline \multirow[b]{3}{*}{ Single MDS component } & & & \multicolumn{4}{|c|}{ CVD } & \multicolumn{4}{|c|}{ Myocardial infarction } & \multicolumn{4}{|c|}{ Stroke } \\
\hline & \multicolumn{2}{|c|}{$\begin{array}{l}\text { All-cause mortality } \\
\qquad(n 553)\end{array}$} & \multicolumn{2}{|c|}{$\begin{array}{l}\text { Incidence } \\
\quad(n 755)\end{array}$} & \multicolumn{2}{|c|}{$\begin{array}{l}\text { Mortality } \\
(n \text { 223) }\end{array}$} & \multicolumn{2}{|c|}{$\begin{array}{l}\text { Incidence } \\
\quad(n 161)\end{array}$} & \multicolumn{2}{|c|}{$\begin{array}{l}\text { Mortality } \\
(n 64)\end{array}$} & \multicolumn{2}{|c|}{$\begin{array}{l}\text { Incidence } \neq \\
\quad(n 167)\end{array}$} & \multicolumn{2}{|c|}{$\begin{array}{l}\text { Mortality } \\
\text { (n 40) }\end{array}$} \\
\hline & $\mathrm{HR}$ & $95 \% \mathrm{Cl}$ & HR & $95 \% \mathrm{Cl}$ & $\mathrm{HR}$ & $95 \% \mathrm{Cl}$ & $\mathrm{HR}$ & $95 \% \mathrm{Cl}$ & $\mathrm{HR}$ & $95 \% \mathrm{Cl}$ & $\mathrm{HR}$ & $95 \% \mathrm{Cl}$ & $\mathrm{HR}$ & $95 \% \mathrm{Cl}$ \\
\hline \multicolumn{15}{|l|}{ Intake above the median } \\
\hline Fat ratio & 0.93 & $0.79,1.10$ & 0.92 & $0.80,1.06$ & 0.92 & $0.71,1.20$ & 0.76 & $0.55,1.03$ & 0.68 & $0.41,1.11$ & 0.90 & $0.67,1.22$ & 1.32 & $0.70,2.51$ \\
\hline Vegetables & $0.81^{*}$ & $0.68,0.96$ & 0.88 & $0.76,1.02$ & 0.81 & $0.62,1.06$ & $0.73^{*}$ & $0.54,1.00$ & $0.58^{*}$ & $0.35,0.96$ & 0.94 & $0.69,1.27$ & 0.90 & $0.48,1.68$ \\
\hline Fruit & $0.74^{\star \star \star}$ & $0.62,0.88$ & $0.86^{*}$ & $0.75,1.00$ & $0.72^{*}$ & $0.55,0.94$ & 1.01 & $0.73,1.38$ & 0.85 & $0.52,1.42$ & 0.87 & $0.64,1 \cdot 18$ & 0.59 & $0.31,1.12$ \\
\hline Cereal grains & 0.97 & $0.82,1.15$ & 0.90 & $0.78,1.04$ & $0.76^{*}$ & $0.58,1.00$ & 0.90 & $0.66,1.24$ & 0.69 & $0.41,1.16$ & 0.82 & $0.60,1.11$ & 1.00 & $0.53,1.89$ \\
\hline Fish and shellfish & 1.05 & $0.88,1.24$ & 0.90 & $0.78,1.04$ & $1 \cdot 12$ & $0.86,1.46$ & 1.02 & $0.75,1.39$ & $1 \cdot 12$ & $0.68,1.85$ & 1.01 & $0.74,1.37$ & 1.38 & $0.72,2.63$ \\
\hline Total alcohol & 1.09 & $0.92,1.29$ & 1.14 & $0.98,1.31$ & 1.24 & $0.95,1.62$ & 0.98 & $0.72,1.35$ & 1.32 & $0.80,2 \cdot 20$ & 1.33 & $0.98,1.81$ & 1.48 & $0.78,2 \cdot 81$ \\
\hline Wine & 1.00 & $0.84,1.18$ & 0.93 & $0.80,1.07$ & 0.91 & $0.70,1 \cdot 19$ & 0.96 & $0.70,1.32$ & 1.03 & $0.63,1.70$ & 1.05 & $0.77,1.43$ & 0.89 & $0.47,1.68$ \\
\hline \multicolumn{15}{|l|}{ Intake below the median } \\
\hline Dairy products & 1.00 & $0.84,1.18$ & 1.02 & $0.89,1.18$ & 0.85 & $0.65,1.11$ & 0.90 & $0.65,1.22$ & $0.49^{* \star}$ & $0.30,0.82$ & 0.97 & $0.72,1.33$ & 1.06 & $0.56,2.02$ \\
\hline Meat products & 0.96 & $0.81,1.14$ & 0.91 & $0.79,1.06$ & 0.87 & $0.67,1.15$ & 0.89 & $0.65,1.23$ & 1.06 & $0.64,1.74$ & 0.89 & $0.65,1.22$ & 0.82 & $0.43,1.58$ \\
\hline
\end{tabular}

MDS, Mediterranean Diet Score.

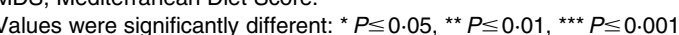

† All results were obtained from a Cox proportional hazards model, adjusted for sex, BMI, education, physical activity and cigarette smoking.

$\ddagger$ Fatal and non-fatal cases. 


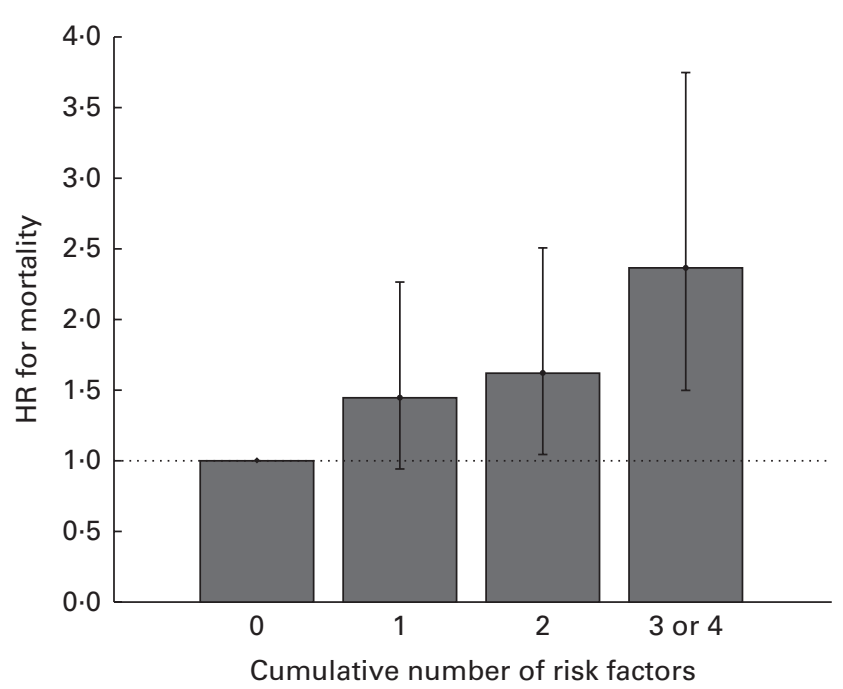

Fig. 1. Association between a cumulative number of risk factors related to both diet and lifestyle (including a modified Mediterranean Diet Score $\leq 4$, ever being a smoker, low levels of physical activity and being obese) and all-cause mortality (adjusted by age). Values are hazard ratios (HR), with $95 \% \mathrm{Cl}$ represented by vertical bars. $P$ for trend $<0.0001$. Cumulative number of risk factors: $0-n 144$ (HR 1); $1-n 606$ (HR 1.45, $95 \% \mathrm{Cl} 0.93$, 2.26); $2-n 787$ (HR 1.62, $95 \% \mathrm{Cl} 1.05,2.51$ ); 3 or $4-n 312$ (HR 2.37, $95 \% \mathrm{Cl} 1.50,3.75)$.

mortality was strong and significant (HR 2.37; 95\% CI 1.50, 3.75; $P$ for trend $<0 \cdot 0001)$.

\section{Discussion}

The present study shows that the MDS was inversely associated both with all-cause mortality and with cardiovascular incidence and mortality, but not with stroke incidence and mortality. All associations proved to be robust to the adjustment for several potential confounders (i.e. sex, BMI, education, physical activity and smoking status) as well as covariates potentially related to possible pathways of $\mathrm{CV}$ risk, such as blood pressure, blood lipids and, notably, weight change after 11 years of follow-up. Increasing the number of unhealthy dietary or lifestyle-related factors additively increased the mortality risk by more than two times compared with those with no risk factors, as suggested by previous studies ${ }^{(29,30)}$. Fruit and vegetables were particularly relevant, as they attenuated the association of the diet score with some outcomes when excluded from score calculations.

Notably, only the MDS including ingredients from mixed dishes and recipes produced statistically significant results. It is not clear how ingredients have been treated in previous studies $^{(9,29,31,32)}$. The present results imply that they should be included in the calculations of this score, because they allow for a more accurate depiction of a Mediterraneanlike dietary pattern.

CVD prevention is of major public health importance, because of the negative impact of CVD on the quality of life ${ }^{(33)}$ and the expected increase in the number of deaths ${ }^{(34)}$. Lifestyle changes and particularly dietary interventions are costeffective means for the prevention of CVD and the reduction of the social and economic burden of this condition ${ }^{(35)}$.
Several studies ${ }^{(13,29,32)}$ have shown associations between the adoption of a Mediterranean dietary pattern and the lower risk of overall mortality and death because of IHD and CVD in general. Particularly, the MDS has been shown to be inversely associated with mortality in Swedish elderly ${ }^{(15)}$ and in middle-aged Swedes where an inverse association with cardiovascular mortality (excluding stroke) was found in women and an association with cancer mortality was found in men ${ }^{(17)}$. In the latter study, fruit intake was inversely associated with all-cause mortality in women. The results of the present study again suggest that fruit and vegetable intakes can have particular importance in the reduction of cardiovascular risk. A few years ago, a meta-analysis of prospective studies had calculated a CHD risk reduction of $4 \%$ for each additional portion of fruit and vegetables consumed per day ${ }^{(36)}$. However, the exact mechanisms by which these food items reduce $\mathrm{CV}$ risk are still unclear $^{(37)}$.

We do not have a clear explanation as to why the MDS and its single components were not at all associated with stroke mortality, also when separately analysing haemorrhagic $v$. non-haemorrhagic cases as well as ischaemic $v$. nonischaemic cases. However, a tendency towards an inverse association was found for stroke incidence. Some epidemiological studies have also examined the association between a MDS and the risk of stroke. Among these, some ${ }^{(31,38,39)}$ found an inverse association, while others did not ${ }^{(17,40)}$. Moreover, a recent paper has found an inverse association between adherence to a Mediterranean-like diet and total cerebrovascular disease ${ }^{(41)}$. Stroke mortality, in particular, could be more related to factors such as the use of anticoagulant therapy and the course of related infections, although the influence of the latter on stroke outcome is still debated ${ }^{(42)}$.

Comparing the methodology used in the present study with the one that we had applied previously to elderly Swedes (based on a refined version of the $\operatorname{MDS}^{(15)}$ ), here a further score refinement was possible by adding the components of mixed dishes and recipes, which enabled us to identify the healthiest dietary pattern in relation to the health effects of a Mediterranean-like dietary pattern. Considering the alcohol component, in particular, one point should be noted. Based on the known U-shaped relationship between alcohol intake and CHD, previous studies using the MDS have given one point for moderate alcohol intakes $(<50 \mathrm{~g} / \mathrm{d}$ in men and $25 \mathrm{~g} / \mathrm{d}$ in women) instead of negative scoring for high intakes ${ }^{(43,44)}$. However, since in our cohort only about $10 \%$ of the subjects exceeded these thresholds, we decided to categorise alcohol intakes according to medians, as for the other food items.

The strengths of the present study include the adjustment of the analyses for several potential confounders as well as for covariates potentially related to possible pathways of cardiovascular risk such as blood pressure and lipids, our ability to examine effects on both MI and stroke, and the availability of a detailed food database based on a validated dietary assessment method that provided details of ingredients from mixed dishes and recipes. Additionally, there is almost $100 \%$ follow-up for endpoints in the Danish registries as well as $100 \%$ coverage of the Danish population ${ }^{(45)}$, which means a 
negligible loss to follow-up. However, some limitations must also be acknowledged, such as possible residual confounding due to physical activity, as well as the likelihood that diets could have been misreported. However, random misreporting would have resulted in attenuation and not inflation of the hazards, suggesting that the observed significant association is likely to be true.

In conclusion, the present Danish population study demonstrates that within a Nordic setting, a high MDS is associated with longer survival and with a reduction in cardiovascular mortality, particularly, MI. Fruit and vegetable intakes seem to be of particular importance in influencing the strength of this association. Thus, the study supports evidence that the Mediterranean diet may be beneficial to health even among populations outside the Mediterranean basin. This is of importance considering that in Europe this pattern is not so common any more among the young generation ${ }^{(46)}$.

\section{Acknowledgements}

The present study was supported by a grant from the Frejaprogramme from the Danish medical research foundation. We thank Kirsten Mehlig from the University of Gothenburg for the statistical advice. G. T. received salary support from the Swedish Council on Working Life and Social Research (FAS) EpiLife centre. The authors' responsibilities were as follows: G. T. performed the statistical analyses and wrote the paper; L. L. helped with the statistical analyses and their interpretation and provided comments on the manuscript; D. S. provided the dataset, helped with the statistical analyses and their interpretation and provided comments on the manuscript; K. Z. W. contributed to food group classification and provided comments on the manuscript; B. L. H. coordinated the research, helped with the statistical analyses and their interpretation and provided comments on the manuscript. All authors read and approved the final manuscript. The authors declare no conflicts of interest.

\section{References}

1. WHO/FAO (2003) Diet, Nutrition and the Prevention of Chronic Diseases. Joint WHO/FAO Expert Consultation. WHO Technical Report Series no. 916. Geneva: WHO/FAO.

2. AICR (2007) Food, Nutrition, Physical Activity and the Prevention of Cancer: A Global Perspective. Washington DC: AICR.

3. Allender S, Peto V, Scarborough P, et al. (2008) Coronary Heart Disease Statistics. London: British Heart Foundation. http://www.heartstats.org

4. Willett WC, Sacks F, Trichopoulou A, et al. (1995) Mediterranean diet pyramid: a cultural model for healthy eating. Am J Clin Nutr 61, Suppl. 6, 1402S-1406S.

5. Alain JN, Katja S-Z, Heiner CB, et al. (2011) Meta-analysis comparing Mediterranean to low-fat diets for modification of cardiovascular risk factors. Am J Med 124, 841-851.

6. Sofi F, Abbate R, Gensini GF, et al. (2010) Accruing evidence on benefits of adherence to the Mediterranean diet on health: an updated systematic review and meta-analysis. Am J Clin Nutr 92, 1189-1196.
7. Sofi F, Cesari F, Abbate R, et al. (2008) Adherence to Mediterranean diet and health status: meta-analysis. BMJ 337, a1344.

8. Martinez-Gonzalez MA, Guillen-Grima F, De Irala J, et al. (2012) The Mediterranean diet is associated with a reduction in premature mortality among middle-aged adults. $J$ Nutr 142, 1672-1678.

9. Trichopoulou A, Kouris-Blazos A, Wahlqvist ML, et al. (1995) Diet and overall survival in elderly people. BMJ 311, 1457-1460.

10. McNaughton SA, Bates CJ \& Mishra GD (2012) Diet quality is associated with all-cause mortality in adults aged 65 years and older. $J$ Nutr 142, 320-325.

11. Buckland G, Agudo A, Travier N, et al. (2011) Adherence to the Mediterranean diet reduces mortality in the Spanish cohort of the European Prospective Investigation into Cancer and Nutrition (EPIC-Spain). Br J Nutr 106, $1581-1591$.

12. Lagiou P, Trichopoulos D, Sandin S, et al. (2006) Mediterranean dietary pattern and mortality among young women: a cohort study in Sweden. Br J Nutr 96, 384-392.

13. Mitrou P, Kipnis V, Thiebaut A, et al. (2007) Mediterranean dietary pattern and prediction of all-cause mortality in a US population: results from the NIH-AARP Diet and Health Study. Arch Intern Med 167, 2461-2468.

14. Osler M \& Schroll M (1997) Diet and mortality in a cohort of elderly people in a north European community. Int J Epidemiol 26, 155-159.

15. Tognon G, Rothenberg E, Eiben G, et al. (2011) Does the Mediterranean diet predict longevity in the elderly? A Swedish perspective. Age (Dordr) 33, 439-450.

16. Sjogren P, Becker W, Warensjo E, et al. (2010) Mediterranean and carbohydrate-restricted diets and mortality among elderly men: a cohort study in Sweden. Am J Clin Nutr 92, 967-974.

17. Tognon G, Nilsson LM, Lissner L, et al. (2012) The Mediterranean diet score and mortality are inversely associated in adults living in the subarctic region. I Nutr $\mathbf{1 4 2}$, $1547-1553$.

18. Martinez E, Llull R, Del Mar Bibiloni M, et al. (2010) Adherence to the Mediterranean dietary pattern among Balearic Islands adolescents. Br J Nutr 103, 1657-1664.

19. di Giuseppe R, Bonanni A, Olivieri M, et al. (2008) Adherence to Mediterranean diet and anthropometric and metabolic parameters in an observational study in the "Alto Molise' region: the MOLI-SAL project. Nutr Metab Cardiovasc Dis 18, 415-421.

20. Garcia-Closas R, Berenguer A \& Gonzalez CA (2006) Changes in food supply in Mediterranean countries from 1961 to 2001. Public Health Nutr 9, 53-60.

21. Forebyggelseskommissionen (2009) Vi kan leve længere og sundere - Forebyggelseskommissionens anbefalinger til en styrket forebyggende indsats (We can live longer and healthier - Prevention Commission's recommendations for enhanced prevention efforts). http://www.forebyggelses kommissionen.dk

22. Eiben G, Andersson CS, Rothenberg E, et al. (2007) Secular trends in diet among elderly Swedes - cohort comparisons over three decades. Public Health Nutr 7, 637-644.

23. Osler M, Heitmann BL \& Schroll M (1997) Ten year trends in the dietary habits of Danish men and women. Cohort and cross-sectional data. Eur J Clin Nutr 51, 535-541.

24. Hartz AJ, Rupley DC \& Rimm AA (1984) The association of girth measurements with disease in 32,856 women. Am J Epidemiol 119, 71-80. 
25. Jensen KH \& Jorgensen T (1991) Incidence of gallstones in a Danish population. Gastroenterology 100, 790-794.

26. Heitmann BL (1991) Body fat in the adult Danish population aged 35-65 years: an epidemiological study. Int J Obes 15, $535-545$.

27. Schofield WN (1985) Predicting basal metabolic rate, new standards and review of previous work. Hum Nutr Clin Nutr 39, Suppl. 1, 5-41.

28. Heitmann B (1992) The effects of gender and age on associations between blood lipid levels and obesity in Danish men and women aged 35-65 years. J Clin Epidemiol 45, 693-702.

29. Knoops KT, de Groot LC, Kromhout D, et al. (2004) Mediterranean diet, lifestyle factors, and 10-year mortality in elderly European men and women: the HALE project. JAMA 292, 1433-1439.

30. van den Brandt PA (2011) The impact of a Mediterranean diet and healthy lifestyle on premature mortality in men and women. Am J Clin Nutr 94, 913-920.

31. Fung T, Rexrode K, Mantzoros C, et al. (2009) Mediterranean diet and incidence of and mortality from coronary heart disease and stroke in women. Circulation 119, e379.

32. Trichopoulou A, Costacou T, Bamia C, et al. (2003) Adherence to a Mediterranean diet and survival in a Greek population. $N$ Engl J Med 348, 2599-2608.

33. Kahn R, Robertson RM, Smith J, et al. (2008) The impact of prevention on reducing the burden of cardiovascular disease. Diabetes care 118, 576-585.

34. WHO (2012) World health statistics 2012. http://www.who.int/ gho/publications/world_health_statistics/EN_WHS2012_Full.pdf

35. Nishida C, Uauy R \& Kumanyika S (2004) The joint WHO/FAO expert consultation on diet, nutrition and the prevention of chronic diseases: process, product and policy implications. Public Health Nutr 7, 245-250.

36. Dauchet L, Amouyel P, Hercberg S, et al. (2006) Fruit and vegetable consumption and risk of coronary heart disease: a meta-analysis of cohort studies. J Nutr 136, 2588-2593.
37. Dauchet L, Amouyel P \& Dallongeville J (2009) Fruits, vegetables and coronary heart disease. Nat Rev Cardiol 6 , 599-608.

38. Agnoli C, Krogh V, Grioni S, et al. (2011) A priori-defined dietary patterns are associated with reduced risk of stroke in a large Italian cohort. J Nutr 141, 1552-1558.

39. Kastorini C-M, Milionis H, Kantas D, et al. (2011) Adherence to the Mediterranean diet in relation to ischemic stroke nonfatal events in nonhypercholesterolemic and hypercholesterolemic participants: results of a case/case-control study. Angiology 63, 509-515.

40. Gardener H, Wright C, Gu Y, et al. (2011) Mediterraneanstyle diet and risk of ischemic stroke, myocardial infarction, and vascular death: the Northern Manhattan Study. Am J Clin Nutr 94, 1458-1522.

41. Misirli G, Benetou V, Lagiou P, et al. (2012) Relation of the traditional Mediterranean diet to cerebrovascular disease in a Mediterranean population. Am $J$ Epidemiol 176, $1185-1192$.

42. Roquer J, Cuadrado-Godia E, Giralt-Steinthauer E, et al. (2012) Previous infection and stroke: a prospective study. Cerebrovasc Dis 33, 310-315.

43. Milaneschi Y, Bandinelli S, Corsi AM, et al. (2011) Mediterranean diet and mobility decline in older persons. Exp Gerontol 46, 303-308.

44. Romaguera D, Guevara M, Norat T, et al. (2011) Mediterranean diet and type 2 diabetes risk in the European Prospective Investigation into Cancer and Nutrition (EPIC) study: the InterAct project. Diabetes Care 34, 1913-1918.

45. Abildstrom SZ, Torp-Pedersen C \& Madsen M (2011) Register-based studies of cardiovascular disease. Scand J Public Health 39, Suppl. 7, 165-169.

46. Tognon G, Hebestreit A, Lanfer A, et al. (2013) Mediterranean diet, overweight and body composition in children from eight European countries: cross-sectional and prospective results from the IDEFICS study. Nutr Metab Card Dis (In Press). 